\title{
Why is monoalkylation versus bis-alkylation of the Ni(II) complex of the Schiff base of $(S)-N$-(2-benzoylphenyl)-1-benzylpyrrolidine- 2-carboxamide and glycine so selective? MP2 modelling and topological QTAIM analysis of chiral metallocomplex synthons of $\alpha$-amino acids used for the preparation of radiopharmaceuticals for positron emission tomography
}

\author{
Alexander Popkov • Martin Breza \\ Received: 3 August 2010/Published online: 7 September 2010 \\ (C) The Author(s) 2010. This article is published with open access at Springerlink.com
}

\begin{abstract}
Chiral Ni(II) complexes are used for the preparation of carbon-11 or fluorine-18 enantiomerically pure $\alpha$-amino acids for positron emission tomography (PET). They enable the selective monoalkylation of a glycine synthon with high stereoselectivity and the preparation of enantiomerically pure $\alpha$-amino acids with quarternary $\alpha$-carbon. Molecular modelling of non-, mono- and di-substituted complexes using quantum theory of atomsin-molecule (QTAIM) topological analysis of electron density allowed us to formulate a new theory explaining the reasons for highly selective monomethylation of the complexes. In the non-substituted complex (GK), the $\alpha$ carbon atom exhibits a higher atomic volume and a more positive charge in comparison with mono- and di-substituted complexes. This unusual behaviour is accompanied by increasing the bond critical point (BCP) ellipticity of the iminic bond in GK explained by the higher mechanical
\end{abstract}

\footnotetext{
A. Popkov

Department of Theoretical Chemistry, Zernike Institute for Advanced Materials, University of Groningen, Nijenborgh 4, 9747 AG Groningen, The Netherlands
}

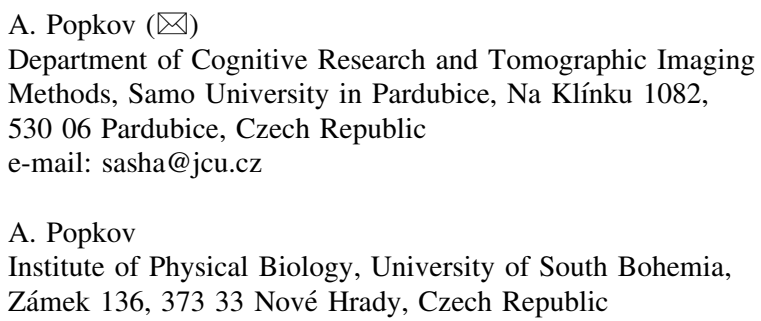

\section{Breza}

Department of Physical Chemistry, Faculty of Chemical and Food Technology, Slovak University of Technology, 81237 Bratislava, Slovak Republic strain. Both phenomena indicate the increased reactivity and probably originate in more compact core of GK where shorter distances in the internal coordination sphere result in the higher strain of its bonds.

Keywords Selective alkylation - Amino acids · Positron emission tomography - Topological analysis of electron density · Quantum theory of atoms-in-molecule

\section{Introduction}

Since their introduction in 1982 [1], chiral Ni(II) complexes-based synthons of $\alpha$-amino acids gained noticeable popularity as a very simple, robust and cheap tool for the preparation of enantiomerically pure non-coded amino acids and diagnostics of brain tumours and malfunction of dopaminergic neurons by positron emission tomography (PET) [2-12].

An important improvement occurred when the first generation synthons based on substituted 2-aminobenzaldehyde (as biomimetic analogues of pyridoxal-5-phosphate) [13] were overperformed in asymmetric alkylation reactions by derivatives of 2-aminoacetophenone followed by even more efficient derivatives of 2-aminobenzophenone [14]. The second generation synthons delivered a higher selectivity of C19 monomethylation and much higher ratio of diastereomers of alkylated products under thermodynamically controlled conditions when C19 is epimerised in a basic reaction mixture or in a separate epimerisation step carried out in $\mathrm{NaOMe} / \mathrm{MeOH}[15,16]$ (Y. N. Belokon, personal communication). For example, equilibrium ratio of diastereomers of the alanine complex increased from $15 \%$ d.e. for the first generation to $82 \%$ d.e. 
Scheme 1 Selective

monomethylation of the secondgeneration synthon. For the 2-aminobenzophenone-derived complex (GK) a bulkier electrofile can be used in the second alkylation step for the preparation of enantiomerically pure $\alpha$-methyl amino acids
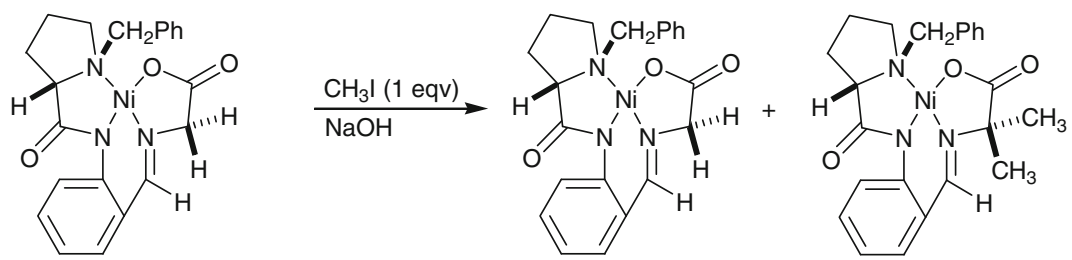
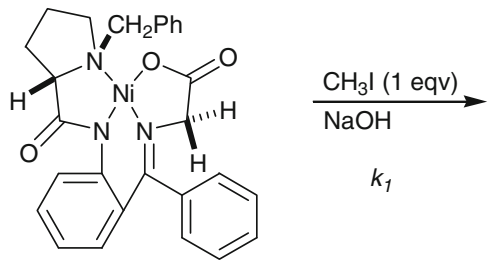

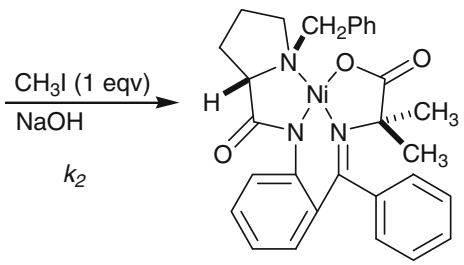

cca $80 \%$
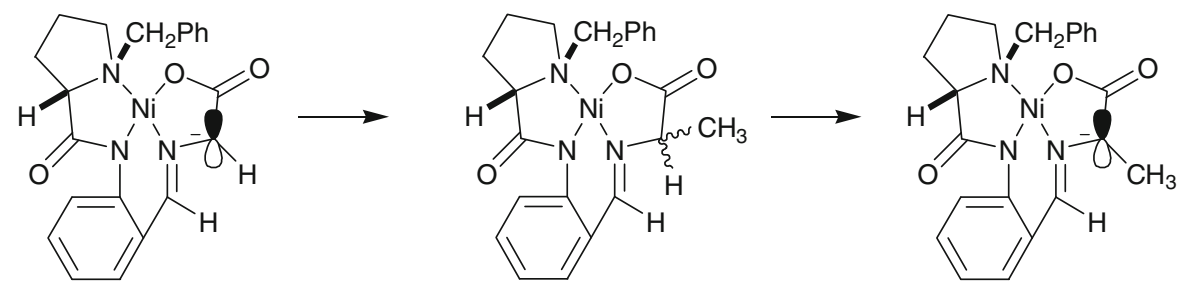

\section{2-aminobenzaldehyde} derived complexes
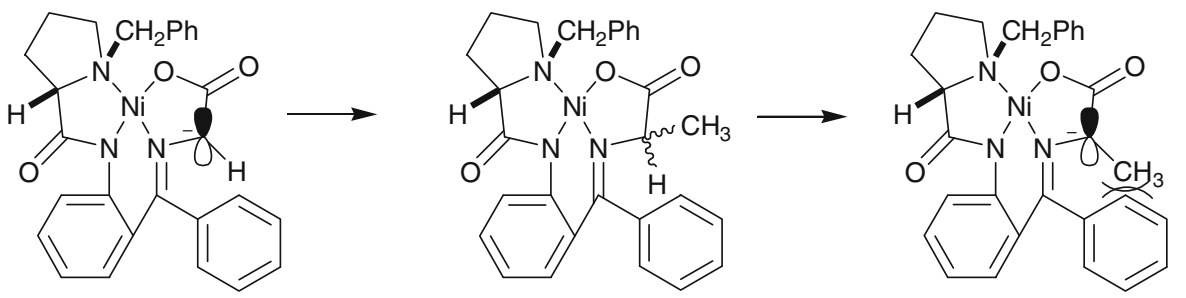

2-aminobenzophenone derived complexes

Scheme 2 Steric repulsion leading to the distortion of the sterically hindered monomethylated carbanion

for the second generation [15]. New synthons enabled the preparation of enantiomerically pure $\alpha$-methyl amino acids by sequential monomethylation of the glycine complex followed by the introduction of a bulkier second C19 substituent (Scheme 1) [17].

This high selectivity was explained by the destabilisation of a carbanion generated from the monomethylated product due to intramolecular steric repulsion, when compared to the carbanion generated from the starting nonsubstituted complex (Scheme 2) [18]. Such a distortion leads to a non-planar destabilised carbanion (Scheme 2). In this article we present a complementary explanation based on the disclosure of a non-trivial bond strain in the least sterically hindered Ni(II) complex of the Schiff base of (S)- $N$-(2-benzoylphenyl)-1-benzylpyrrolidine-2-carboxamide and glycine (GK) when compared with its $\alpha$-carbon (C19) monoalkylated (HomoSK) and dimethylated $\left(\mathrm{Me}_{2} \mathrm{GK}\right)$ derivatives (see Scheme 3 and Fig. 1).

\section{Results and discussion}

Recently achieved breakthrough in the reduction of the environmental impact of a high-scale production of $\alpha$-amino acids via $\mathrm{Ni}(\mathrm{II})$ complexes $[19,20]$ and a substantial improvement of the diastereoselectivity of the alkylation reaction [16, 21-25] made the complexes a tool of choice for the preparation of carbon-11 or fluorine-18 enantiomerically pure $\alpha$-amino acids for PET. In order to achieve simple work-up of the reaction mixture after the alkylation reaction, and easy, cheap and environmentfriendly purification of the desired diastereomer of the alkylated complex by the crystallization or simple purification of the reaction mixture in the remote-controlled preparation of labelled $\alpha$-amino acids for PET, it is important to understand and use the factors determining the high ratio of GK alkylation rates $k_{1} / k_{2}$ (Scheme 1). During the course of our development of the approaches to 


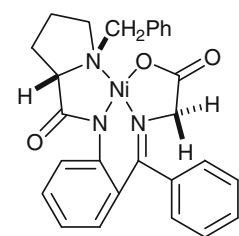

GK

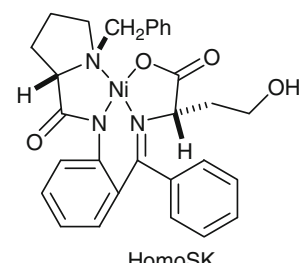

HomoSK

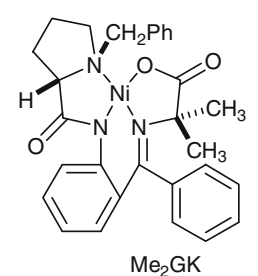

$\mathrm{Me}_{2} \mathrm{GK}$
Scheme 3 Non-, mono- and di-substituted complexes derived from 2-aminobenzophenone

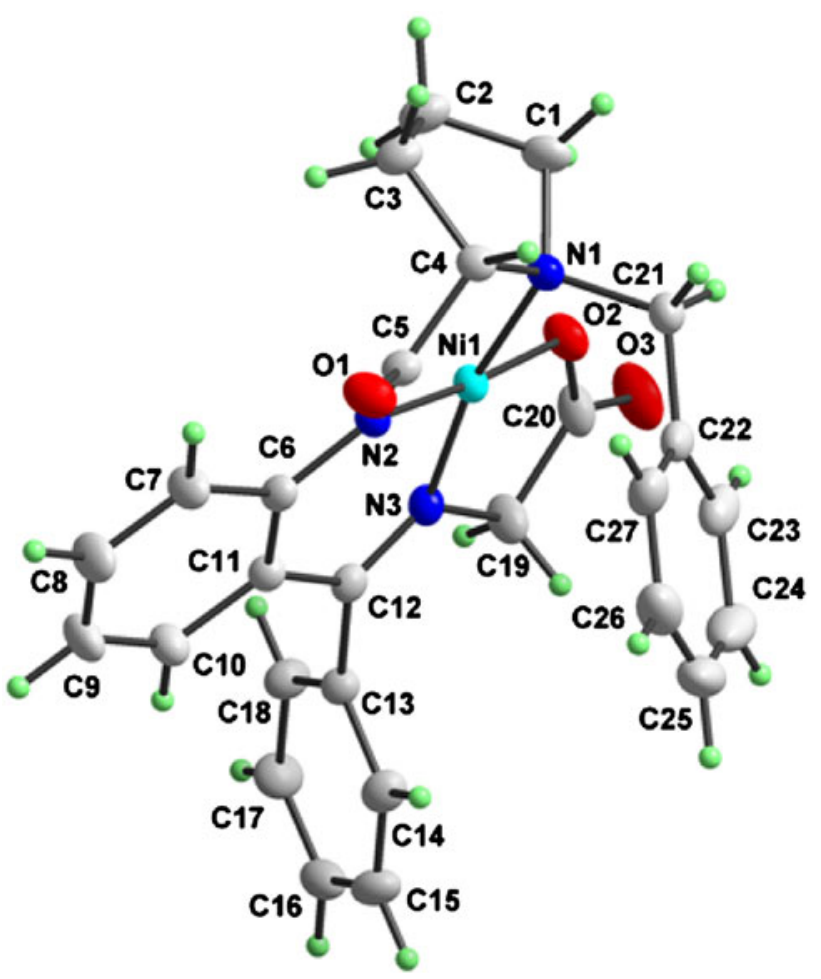

Fig. 1 Numbering scheme for GK (From ref. [26])

carbon-11 labelled $\alpha$-methyl amino acids and to a strategy of fluorine-18 labelling of peptides, we prepared a number of single crystals of nickel (II) complexes and performed ab initio MP2 quantum-chemical modelling of these structures. In this work we describe the quantum theory of atoms-in-molecules (QTAIM) analysis of the atoms and bonds of interest based on MP2 single-point calculations of the non-, mono- and di-substituted complexes, X-ray structures of which we have published previously (Scheme 3) [26-28]. QTAIM analysis based on MP2 calculations using double- $\zeta$ basis sets is considered to be an adequate approach for modelling the large systems where $\pi-\pi$ and $\sigma-\pi$ interactions play an important role [29]. Initially we expected that the introduction of substituents into the $\alpha$-position (C-19) of the complexes should subsequently increase the steric hindrance in these complexes. In reality, the atomic volume of $\mathrm{C}-19$ in the non-substituted GK is the
Table 1 Atomic charges and volumes of selected atoms in the systems under study (see Scheme 3 and Fig. 1)

\begin{tabular}{|c|c|c|c|c|c|c|}
\hline \multirow[t]{2}{*}{ Atoms } & \multicolumn{3}{|c|}{ Charges } & \multicolumn{3}{|c|}{ Volumes $\left(\mathrm{Bohr}^{3}\right)$} \\
\hline & GK & HomoSK & $\mathrm{Me}_{2} \mathrm{GK}$ & GK & HomoSK & $\mathrm{Me}_{2} \mathrm{GK}$ \\
\hline $\mathrm{Ni}$ & +1.29 & +0.98 & +0.98 & 71.7 & 87.6 & 87.0 \\
\hline $\mathrm{O} 2$ & -1.19 & -0.97 & -1.03 & 103.9 & 109.9 & 107.2 \\
\hline $\mathrm{C} 20$ & +1.49 & +1.25 & +1.27 & 37.6 & 42.8 & 41.5 \\
\hline C19 & +0.48 & +0.29 & +0.24 & 47.0 & 44.9 & 41.2 \\
\hline N3 & -1.17 & -0.94 & -0.92 & 88.0 & 81.3 & 81.6 \\
\hline C3 & +0.26 & +0.19 & +0.19 & 51.8 & 56.1 & 54.9 \\
\hline
\end{tabular}

Table 2 BCP electron densities, $\rho_{\mathrm{BCP}}$, and ellipticities, $\varepsilon_{\mathrm{BCP}}$, of selected bonds in the systems under study (see Scheme 3 and Fig. 1)

\begin{tabular}{|c|c|c|c|c|c|c|}
\hline \multirow[t]{2}{*}{ Bonds } & \multicolumn{3}{|c|}{$\rho_{\mathrm{BCP}}\left(\mathrm{e} / \mathrm{Bohr}^{3}\right)$} & \multicolumn{3}{|l|}{$\varepsilon_{\mathrm{BCP}}$} \\
\hline & GK & HomoSK & $\mathrm{Me}_{2} \mathrm{GK}$ & GK & HomoSK & $\mathrm{Me}_{2} \mathrm{GK}$ \\
\hline $\mathrm{Ni}-\mathrm{O} 2$ & 0.101 & 0.116 & 0.114 & 0.424 & 0.072 & 0.085 \\
\hline $\mathrm{O} 2-\mathrm{C} 20$ & 0.327 & 0.223 & 0.215 & 0.089 & 0.015 & 0.016 \\
\hline C20-C19 & 0.249 & 0.237 & 0.230 & 0.064 & 0.067 & 0.068 \\
\hline C19-N3 & 0.234 & 0.297 & 0.318 & 0.048 & 0.014 & 0.005 \\
\hline $\mathrm{Ni}-\mathrm{N} 3$ & 0.119 & 0.105 & 0.111 & 0.215 & 0.147 & 0.157 \\
\hline $\mathrm{C} 2-\mathrm{C} 3$ & 0.232 & 0.215 & 0.226 & 0.018 & 0.020 & 0.018 \\
\hline C3-C4 & 0.225 & 0.207 & 0.215 & 0.032 & 0.034 & 0.034 \\
\hline
\end{tabular}

highest one among the three complexes (Table 1). As a rule, atomic volumes increase with higher electron density at the corresponding atoms (more negative or less positive atomic charges) in analogous structures [30, 31] otherwise an increasing reactivity at these atoms is indicated. In GK, $\mathrm{O} 2$ atom exhibits a lower atomic volume and a more negative charge whereas $\mathrm{C} 19$ atom exhibits a higher volume and a more positive charge in comparison with HomoSK and $\mathrm{Me}_{2} \mathrm{GK}$ complexes (Table 1). This unusual behaviour is accompanied by the increased $\mathrm{BCP}$ ellipticities of $\mathrm{Ni}-\mathrm{O} 2, \mathrm{O} 3-\mathrm{C} 20$ and $\mathrm{C} 19-\mathrm{N} 3$ bonds of $\mathrm{GK}$ in comparison with the remaining complexes (Table 2) which may be explained by the mechanical strain. The increased mechanical strain at $\mathrm{O} 2$ and $\mathrm{C} 19$ atoms indicates the higher reactivity at these sites of GK $[30,31]$ in comparison with HomoSK and $\mathrm{Me}_{2} \mathrm{GK}$ complexes. Significantly stronger $\mathrm{O} 2-\mathrm{C} 20$ bond and weaker C19-N3 bond in GK in comparison with the remaining compounds (Table 2) confirm the observed differences in their electronic structure as well. The atomic volumes of the iminic N3 bonded to C19 follow the similar pattern-they are the biggest in the least substituted GK (Table 1). We hypothesised that such an unexpected behaviour originates in the more compact core of GK where the shorter distances in the internal coordination sphere result in the higher strain of these bonds. Monoalkylated (e.g. monomethylated) complexes derived 
from 2-aminobenzophenone, where the distances between the nickel atom and the heteroatoms are longer, keep a lower strain and thus they are more stable. In the complexes derived from 2-aminobenzaldehyde, the differences are probably not so profound due to a lower steric hindrance, and so there is a little or no energetic benefit of the monosubstitution in such complexes.

\section{Experimental}

The electronic structure of the complexes under study is evaluated at MP2 level of theory using triple- $\zeta$ valence (TZV) basis for Ni [32] and double- $\zeta$ valence (DZV) basis sets for the remaining atoms [33]. Firefly software package is used for single-point calculations of experimental geometries [34].

The electronic structure of the species under study is investigated using QTAIM topological analysis of electron density [33, 34]. The results are evaluated in terms of atomic volumes $V$ and atomic charges $q$ obtained using the electron density integrated over atomic basins (up to $0.001 \mathrm{e}^{\mathrm{B}} \mathrm{Bohr}^{3}$ level). Bond characteristics are evaluated in terms of electron density $\rho$ (proportional to bond strength) and bond ellipticity $\varepsilon$

$\varepsilon=\lambda_{1} / \lambda_{2}-1$

at bond critical points (BCP) where $\lambda_{1}<\lambda_{2}<0<\lambda_{3}$ are the eigenvalues of the Hessian of the BCP electron density. AIM2000 [35] software package is utilized for QTAIM analysis (http://www.aim2000.de/).

\section{Conclusions}

We have disclosed an important factor giving rise to the high selectivity of the monoalkylation of nickel (II) complex of the Schiff base of BPB and glycine-the higher strain of the bonds of this non-substituted complex when compared to its mono- and di-substituted analogues. Further MP2/QTAIM analyses of similar less sterically hindered complexes are desirable to verify our findings.

Acknowledgments The authors thank Dr Jozef Kožíšek for helpful discussion. A. P. acknowledges the support by the Ministry of Education, Youth and Sports of the Czech Republic, project no. ME09062.

Open Access This article is distributed under the terms of the Creative Commons Attribution Noncommercial License which permits any noncommercial use, distribution, and reproduction in any medium, provided the original author(s) and source are credited.

\section{References}

1. Belokon YN, Zeltzer IE, Ryzhov MG, Saporovskaya MB, Bakhmutov VI, Belikov VM (1982) J Chem Soc Chem Commun 180-181

2. Antoni G, Kihlberg T, Långström B (2003) In: Welch MJ, Redvanly CS (eds) Handbook of radiopharmaceuticals. Wiley, Chichester

3. Krasikova RN, Kuznetsova OF, Fedorova OS, Maleev VI, Saveleva TF, Belokon YN (2008) Bioorg Med Chem 16:4994-5003

4. Krasikova RN, Kuznetsova OF, Fedorova OS, Mosevich IK, Maleev VI, Belokon YN, Saveleva TF, Sagyan AS, Dadayan SA, Petrosjan AA (2007) Radiochemistry 49:449-454

5. Fedorova OS, Kuznetsova OF, Mosevich IK, Shatik SV, Kataeva GV, Belokon YN, Krasikova RN (2006) Radiochemistry 48:458-462

6. Krasikova RN, Zaitsev VV, Ametamey SM, Kuznetsova OF, Fedorova OS, Mosevich IK, Belokon YN, Vyskočil Š, Shatik SV, Nader M (2004) Nucl Med Biol 31:597-603

7. Kuznetsova OF, Mosevich IK, Fedorova OS, Korsakov MV, Krasikova RN (2002) Radiochemistry 44:527-532

8. Popkov A, Nádvorník M, Kružberská P, Lyčka A, Lehel S, Gillings NM (2007) J. Labelled Compd Radiopharm 50:370-374

9. Cosgrove KP, Mazure CM, Staley JK (2007) Biol Psychiatry 62:847-855

10. Weissleder R, Pittet MJ (2008) Nature 452:580-589

11. Judenhofer MS, Wehrl HF, Newport DF, Catana C, Siegel SB, Becker M, Thielscher A, Kneilling M, Lichy MP, Eichner M, Klingel K, Reischl G, Widmaier S, Röcken M, Nutt RE, Machulla H-J, Uludag K, Cherry SR, Claussen CD, Eichler BJ (2008) Nat Med 14:459-465

12. Wang J, Lin DZ, Shi JM, Ding X, Zhang L, Jiang HL, Liu H (2010) Synthesis 1205-1208

13. Dunathan HC (1971) Adv Enyzmol Relat Areas Mol Biol 35:79-135

14. Belokon YN, Bulychev AG, Vitt SV, Struchkov YT, Batsanov AS, Timofeeva TV, Tsyryapkin VA, Ryzhov MG, Lysova LA, Bakhmutov VI, Belikov VM (1985) J Am Chem Soc 107:4252-4259

15. Belokon YN, Maleev VI, Vitt SV, Ryzhov MG, Kondrashov YD, Golubev SN, Vauchskii YP, Kazika AI, Novikova MI, Krasutskii PA, Yurchenko AG, Dubchak IL, Shklover VE, Struchkov YT, Bakhmutov VL, Belikov VM (1985) J Chem Soc Dalton Trans 17-26

16. Popkov A, Hanusek J, Čermák J, Langer V, Jirásko R, Holčapek M, Nádvorník M (2010) J Radioanal Nucl Chem 285:621-626. doi:10.1007/s10967-010-0578-5

17. Popkov A, Nádvorník M, Langer V, Jirásko R, Holčapek M, Lyčka A (2007) J Labelled Compd Radiopharm 50:554-555

18. Terekhova MI, Belokon YN, Maleev VI, Chernoglazova NI, Kochetkov KA, Belikov VM, Petrov ES (1985) Izv Akad Nauk SSSR Ser Khim 905-908 (English translation: Terekhova MI, Belokon YN, Maleev VI, Chernoglazova NI, Kochetkov KA, Belikov VM, Petrov ES (1986) Bull Acad Sci Div Chem Sci 35:824-828)

19. Nádvorník M, Popkov A (2002) Green Chem 4:71-72

20. Nádvorník M, Langer V, Jirásko R, Holčapek M, Weidlich T, Lyčka A, Popkov A (2008) Polyhedron 27:3477-3483

21. Popkov A, Gee A, Nádvorník M, Lyčka A (2002) Transition Metal Chem 27:884-887

22. Belokon YN, Saporovskaya MB, Backhmutov VI, Timofeeva TV, Batsanov AS, Struchkov YT, Belikov VM (1988) Koord Khim 14:1565-1575

23. De BB, Thomas NR (1997) Tetrahedron 8:2687-2691 
24. Saghiyan AS, Hambardzumyan HH, Manasyan LL, Petrosyan AA, Maleev VI, Peregudov AS (2005) Synth Commun 35:449-459

25. Saghiyan AS, Dadayan SA, Petrosyan SG, Manasyan LL, Geolchanyan AV, Djamgaryan SM, Andreasyan SA, Maleev VI, Khrustalev VN (2006) Tetrahedron 17:455-467

26. Popkov A, Langer V, Manorik PA, Weidlich T (2003) Transition Metal Chem 28:475-481

27. Popkov A, Nádvorník M, Kožíšek J (2008) Acta Crystallogr E 64:m364-u826

28. Langer V, Popkov A, Nádvorník M, Lyčka A (2007) Polyhedron 26:911-917

29. Dui D, Frontera A, Escudero D, Ballester P, Costa A, Deyà PM (2008) Theor Chem Acc 120:385-393
30. Bader RFW (1990) Atoms in molecules: a quantum theory. Clarendon Press, Oxford

31. Cortés-Guzmán F, Bader RFW (2005) Coord Chem Rev 249:633-662

32. Rappe AK, Smedley TA, Goddard WA III (1981) J Phys Chem $85: 2607-2611$

33. Dunning TH Jr, Hay PJ (1977) In: Shaefer III HF (ed) Methods of electronic structure theory. Plenum Press, New York

34. Granovsky AA (2009) Firefly version 7.1.G. http://classic.chem. $\mathrm{msu} . \mathrm{su} / \mathrm{gran} /$ firefly/index.html

35. Biegler-König F, Schönbohm J, Bayles D (2001) J Comput Chem 22:545-559 